\title{
Cost-effectiveness analysis of abobotulinumtoxinA for the treatment of cervical dystonia in the United Kingdom
}

This article was published in the following Dove Press journal:

ClinicoEconomics and Outcomes Research

15 April 2017

Number of times this article has been viewed

\author{
Madhusubramanian \\ Muthukumar' \\ Kamal Desai' \\ Seye Abogunrin² \\ Timothy Harrower ${ }^{3}$ \\ Sylvie Gabriel ${ }^{4}$ \\ Jerome Dinet ${ }^{5}$ \\ 'Modelling and Simulation, ${ }^{2}$ Meta \\ Research, Evidera, London, \\ ${ }^{3}$ Royal Devon and Exeter NHS \\ Foundation Trust, Exeter, UK; \\ ${ }^{4}$ Global Market Access and Pricing, \\ ${ }^{5} \mathrm{Health}$ Economics and Outcomes \\ Research (Global), Ipsen Pharma, \\ Boulogne-Billancourt, France
}

Background: Cervical dystonia (CD) involves painful involuntary contraction of the neck and shoulder muscles and abnormal posture in middle-aged adults. Botulinum neurotoxin type A (BoNT-A) is effective in treating CD but little is known about its associated cost-effectiveness.

Objective: To evaluate the cost-effectiveness of abobotulinumtoxinA for treating CD from the UK payer perspective.

Methods: A Markov model was developed to evaluate the cost-effectiveness of abobotulinumtoxinA versus best supportive care (BSC) in $\mathrm{CD}$, with a lifetime horizon and health states for response, nonresponse, secondary nonresponse, and $\mathrm{BSC}$ in patients with $\mathrm{CD}$ (mean age: 53 years; 37\% male). Clinical improvement measured using Toronto Western Spasmodic Torticollis Rating Scale (TWSTRS) was mapped to utility using data from a randomized trial of abobotulinumtoxinA. Health care resource use, costs, and other inputs were from the British National Formulary, Personal Social Services Research Unit, published literature, or expert opinion. Costs and outcomes were discounted at 3.5\% per annum.

Results: In the base case, the incremental lifetime quality-adjusted life-years (QALYs) gained from abobotulinumtoxinA arm versus BSC was 0.253 per patient, whereas the incremental cost was $£ 7,160$, leading to an incremental cost-effectiveness ratio (ICER) of $£ 30,468$ per QALY. One-way sensitivity analyses showed that these results were sensitive to the proportion of responders to abobotulinumtoxinA at first injection, duration between injections, the number of reinjections allowed among primary nonresponders, and any difference in baseline TWSTRS value between the BSC and abobotulinumtoxinA arms. Probabilistic sensitivity analysis showed that abobotulinumtoxinA was cost-effective $46 \%$ and $49 \%$ of times at thresholds of $£ 20,000$ and $£ 30,000$ per QALY, respectively. Scenarios are considered including vial-sharing, productivity losses, secondary response/nonresponse at subsequent injections, 5-year time horizon, and alternative reinjection intervals for BoNT-As produced ICERs ranging from cost-saving to $£ 40,777$ per QALY, versus BSC.

Conclusion: AbobotulinumtoxinA was found to be cost-effective in treating adults with CD, at acceptable willingness-to-pay thresholds in the UK.

Keywords: cost-effectiveness analysis, cervical dystonia, botulinum neurotoxin type A, abobotulinumtoxinA

\section{Introduction}

Dystonia is a disorder that causes involuntary contraction of skeletal muscles, abnormal posture, and severe pain or discomfort. Dystonia may be more common than evidence suggests, owing to under-recognition, misdiagnosis, or late clinical presentation. ${ }^{1,2}$ Cervical dystonia (CD) is the most commonly reported type and mainly affects neck
Meta Research, Evidera, Metro Building, 6th Floor, I Butterwick, Hammersmith, London, W6 8DL, UK

Tel +442085765049

Email seye.abogunrin@evidera.com 
and shoulder muscles in middle-aged patients. ${ }^{3-5} \mathrm{CD}$ 's prevalence in Europe seems to exceed than elsewhere (e.g., up to 233 cases per $1,000,000$ population $^{6}$ vs 89 per $1,000,000$ in the $\mathrm{US}^{7}$ ). Within the UK specifically, data have suggested that there are up to 24,000 cases $^{8}$ although, interestingly, a much higher estimate (up to 70,000 cases) has been proposed by the Dystonia Society. ${ }^{9}$ Data on the associated economic burden of CD are scarce. However, 6-month costs for the US have been estimated as $\$ 1,255$ to $\$ 63,320 .{ }^{8}$ Evidence on lost productivity due to work absenteeism is also sparse, although employment statistics show that at least one-third of patients with CD stop working as the disease progresses. ${ }^{10}$

Conventional therapeutic options for CD include skeletal muscle relaxants, anticholinergics, and rehabilitative therapy. In addition, some patients need deep brain stimulation therapy and selective peripheral denervation. ${ }^{4}$ Pharmacotherapy involving botulinum neurotoxin type A (BoNT-A) injection has also proven effective ${ }^{11,12}$ for $C D$, especially when combined with conventional therapy. By reducing muscle force, such treatment can alleviate pain, increase the range of free movement, and improve resting posture. Consequently, BoNT-A therapy can reduce the everyday care burden of managing $\mathrm{CD}^{13}$ and also improves patients' and potentially, caregivers' quality of life (QoL). BoNT-A usage for $\mathrm{CD}$ has also been shown to result in productivity-related gains through decreased absenteeism and sickness leave. ${ }^{14}$ Also, another study found that, compared with patients on oral medications, more of those on BoNT-A treatments had improvement in employment status (oral medications: 18.5\%; BoNT-As: $66.1 \%$ ) and restoration of full employment with normal productivity (oral medications: 0\%; BoNT-As: $12.9 \%) .{ }^{15}$ Such results may reflect BoNT-As' ability to reduce pain and bring about functional improvements in patients with $\mathrm{CD}$, given the strong association between pain and physical dysfunction with job impairment. ${ }^{16}$

These findings invite questions about the comparative effects of the various BoNT-As available. Currently, three such products are used for CD in the UK: abobotulinumtoxinA (Dysport ${ }^{\circledR}$ : Ipsen Limited, Slough, UK), onabotulinumtoxinA (Botox ${ }^{\circledR}$ : Allergan Limited, Marlow, UK), and incobotulinumtoxinA (Xeomin ${ }^{\circledR}$ : Merz Pharmaceuticals GmbH, Frankfurt/Main, Germany). Of note, although no published head-to-head trials have compared the effectiveness of these BoNT-As, a recent mixed treatment comparison reported similar improvements in scores on the Toronto Western Spasmodic Torticollis Rating Scale (TWSTRS; which comprises three independently scored subscales [severity, disability, pain], with the three scores being summed to give the TWSTRS total score [range $0-87$, best to worst] ${ }^{17}$ ). ${ }^{18,19}$ However, evidence also suggests that these BoNT-As differ in key characteristics, including time to first improvement, maximum benefit derived by patients, duration of symptomatic relief, and costs. ${ }^{8,20}$ This lack of clarity about the relative merits of different BoNT-As in CD is echoed by other key unknowns regarding these drugs. In particular, despite the significant costs of CD to the UK National Health Service(NHS), ${ }^{8}$ there are no published UK data on the associated productivity losses of patients not treated with BoNT-As nor on the cost-effectiveness of these treatments. Little or no evidence exists on cost-effectiveness of BoNT-As for $\mathrm{CD}$ in the UK, although one study ${ }^{21}$ showed BoNT-As to be cost-effective over a 1-year time horizon relative to $\mathrm{BSC}$ from the US government perspective.

With such data gaps in mind, we used economic modeling to assess the cost-effectiveness of abobotulinumtoxinA and other BoNT-As versus best supportive care (BSC) as treatment for $\mathrm{CD}$, from the perspective of the UK NHS and Personal Social Services (PSS). For these purposes, BSC comprised oral medications (including benzodiazepines, baclofen, and anticholinergic agents), deep brain stimulation, and selective peripheral denervation.

\section{Methods}

\section{Overview}

Ethical permission was not required for this study as it was based purely on secondary data. A Markov model ${ }^{22,23}$ with a 3 -month cycle duration was developed in Microsoft Excel ${ }^{\circledR}$ (2010) to predict the costs, benefits, and incremental costeffectiveness ratios (ICERs) per life-year and quality-adjusted life-year (QALY) from initiation of BoNT-A therapy or BSC over an analytic time horizon (lifetime in base case; varied in scenario analyses) or until death. The analysis adopted the perspective of the UK NHS and PSS. Model costs and outcomes were discounted at $3.5 \%$ per annum based on the National Institute for Health and Care Excellence reference case. $^{24}$ The currency year for the analyses was 2013.

Key characteristics of the population in the model were intended to closely match those in an abobotulinumtoxinA trial. ${ }^{25}$ In this study, the mean age was 53.0 years (standard deviation [SD]: 13.0 years); 37\% were males and the mean baseline total TWSTRS score was 44.9 (SD: 8.4). As there is no evidence that $\mathrm{CD}$ increases mortality risk, the model calculated age-specific mortality using interim life tables from the UK Office for National Statistics. ${ }^{26}$ 


\section{Model structure}

Figure 1 presents the model structure for the BoNT-A and BSC arms, which was informed by consultation with clinical experts. In the BoNT-A arm, patients with CD starting active treatment are divided into two health states: "no response" or "response." Response was defined as an improvement in TWSTRS from baseline of at least $20 \%$ at week 4 or 8 or 12 , in the base case (higher improvement in TWSTRS from baseline ( $\geq 30 \%$ ) has been tested as part of alternative scenario analysis). Owing to unavailability of data, it was assumed that patients not responding to the initial injection do not achieve response in subsequent injection cycles. Similarly, patients who respond to the initial injection are assumed not to develop secondary nonresponse. Accordingly, only the first injection cycle determines the number of responding and nonresponding patients throughout the model. In an alternative scenario, the model assumed that nonresponders could achieve response with subsequent reinjections given at higher doses. Before treatment discontinuation, nonresponders are allowed up to six BoNT-A reinjections (with electromyographic or ultrasound guidance) before moving to $\mathrm{BSC}$. Initial responders were allowed to receive up to four reinjections before becoming secondary nonresponders and may require investigations (a frontalis or anti-BoNT-A antibody titer test) to determine whether they are resistant to the BoNT-A, before they move to BSC. The enforced discontinuation after these cycles of nonresponse is modeled using tunnel states in the Markov design. Additionally, patients receiving BoNT-A may discontinue treatment due to causes such as loss of effect, severe adverse events (AEs), or other reasons according to an annual discontinuation rate. Once patients discontinue treatment, they move on to BSC. At all health states, patients can die. In the nonactive treatment (BSC) arm, patients start and remain in BSC state until death.

Dysphagia is a commonly reported AE that may impair the patient's QoL or carry certain management costs. Disutility and costs associated with dysphagia were included in the model for the proportion of patients who experience it, but it was assumed not to cause treatment discontinuation.

\section{Model inputs \\ Efficacy inputs}

Data on clinical efficacy (improvements in TWSTRS) were derived from the Phase III placebo-controlled trial

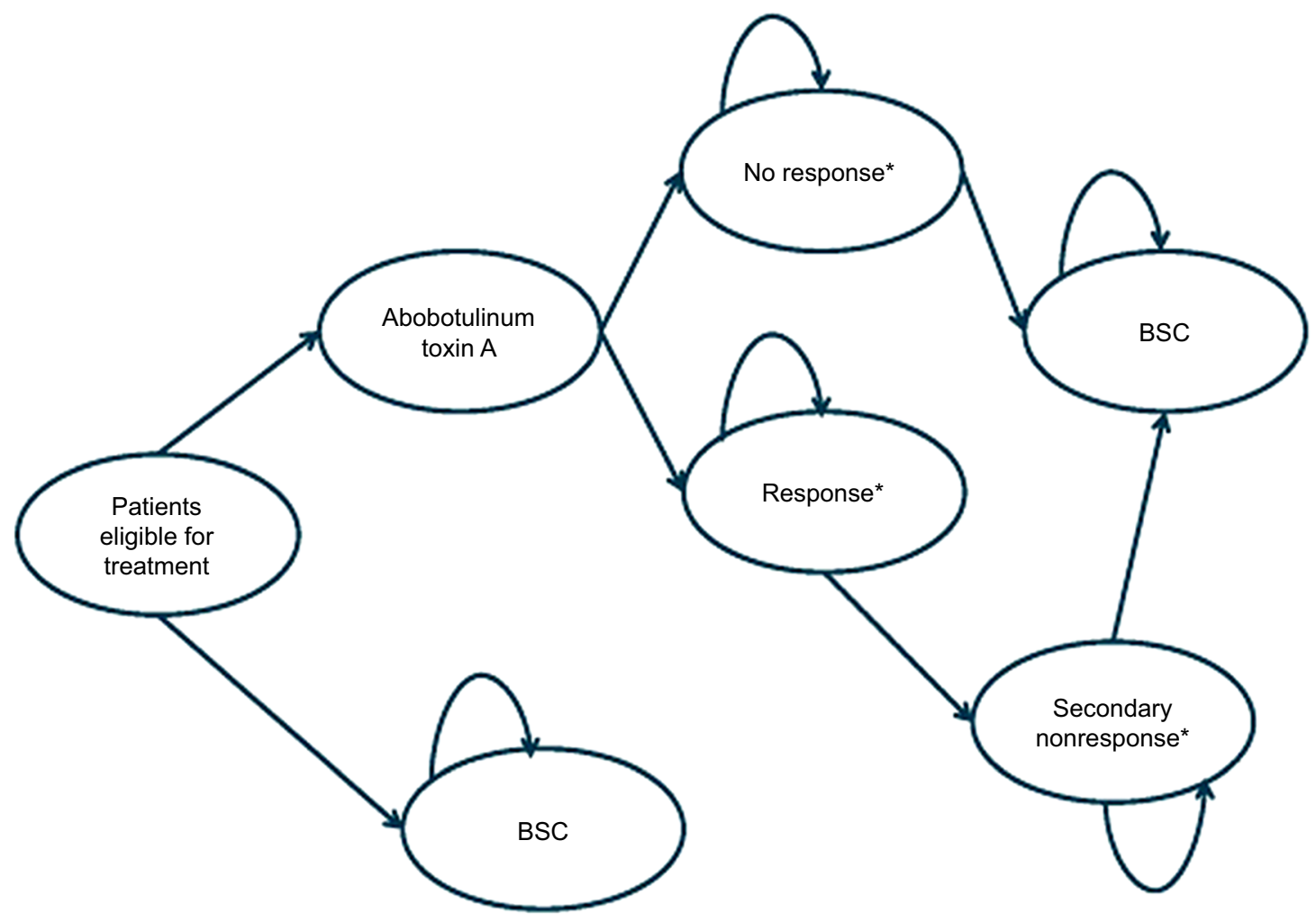

Figure I Model structure.

Notes: *Level of response is based on average change of TWSTRS from baseline in the three groups from trial reanalysis. TWSTRS and quality of life are tracked for each health state. All patients at any state are at risk of death.

Abbreviations: BSC, best supportive care; TWSTRS, Toronto Western Spasmodic Torticollis Rating Scale. 
of abobotulinumtoxinA (NCT00288509). ${ }^{25}$ In this study, compared with placebo, a abobotulinumtoxinA produced significant decreases from baseline in the mean TWSTRS total scores compared with placebo at week 4 (-15.6, SD: 2.0 vs -6.7 , SD: $2.0 ; p<0.001)$ with significant improvements sustained to week 12 (-9.1, SD: 1.7 vs -4.9 , SD: 1.7 ; $p=0.019) .{ }^{25}$ The model assumed that within a model cycle, which was set to be equal to one injection cycle, responders to BoNT-A could experience a sharp improvement in the total TWSTRS score by week 4 , with this peaking at week 8 , and then waning by week 12 . It also assumed that the TWSTRS score at the end of each cycle did not return fully to the baseline value due to residual benefit from BoNT-A as shown in Figure S1. It was also assumed that patients on BSC could benefit from minor improvements in TWSTRS compared to baseline.

Other clinical inputs such as reinjection interval, annual rate of all-cause treatment discontinuation, and $\mathrm{AE}$ rates for dysphagia per injection are given in Table S1, with corresponding assumptions.

\section{Utility inputs}

For the model, death was assigned a utility of 0 and 1 represented a state of perfect health. Utility data were derived from the Phase III trial of abobotulinumtoxinA.${ }^{25}$ Specifically, the relationship between TWSTRS and utility was determined using a repeated-measures logistic regression analysis on the 36-item Short Form Health Survey and TWSTRS data at baseline or week 12 (Table S2, Figure 2). A preference-based value set was applied to patient responses to the 36-item Short Form Health Survey to obtain utilities. In the model, utility was linked at all times to the TWSTRS score such that improvement or worsening of TWSTRS corresponded with an increasing or decreasing utility. The calculated baseline utility and utility gains at weeks $0,4,8$, and 12 are detailed in Table 1.

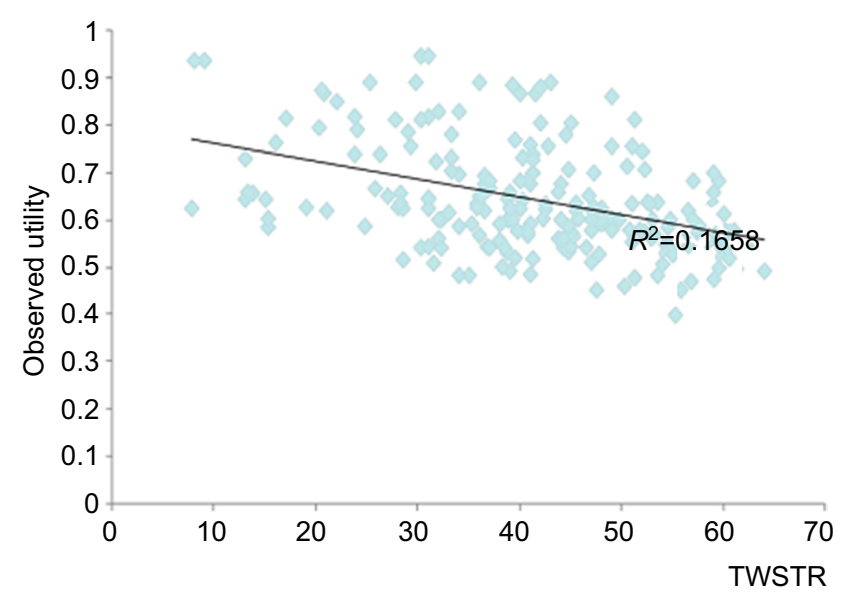

Figure 2 Graphical representation of linkage between utility and TWSTRS estimated from analysis of abobotulinumtoxinA trial. Data extrapolated from a previous study. ${ }^{25}$

Notes: The line represents the best fit to the available data given by the blue points showing reduced utility with higher TWSTRS total score.

Abbreviation: TWSTRS, Toronto Western Spasmodic Torticollis Rating Scale.

Table I Discounted costs and health outcomes in base-case analysis

\begin{tabular}{|c|c|c|c|}
\hline Costs & AbobotulinumtoxinA ( $(€)$ & $\begin{array}{l}\text { BSC without BoNT-A } \\
\text { injections }(\epsilon)\end{array}$ & $\begin{array}{l}\text { Incremental (AbobotulinumtoxinA } \\
\text { vs BSC) (E) }\end{array}$ \\
\hline Drug cost & 5,188 & 0 & 5,188 \\
\hline $\begin{array}{l}\text { Concomitant medications } \\
\text { cost }\end{array}$ & 429 & 488 & -59 \\
\hline Drug administration cost & 4,600 & 0 & 4,600 \\
\hline Disease management cost & 6,300 & 8,869 & $-2,569$ \\
\hline Indirect cost & - & - & - \\
\hline Total cost & 16,517 & 9,357 & 7,160 \\
\hline Health outcomes & AbobotulinumtoxinA & BSC without BoNT-A injections & Incremental \\
\hline Life-years & 18.042 & 18.042 & 0.000 \\
\hline QALYs & 11.970 & 11.735 & 0.235 \\
\hline \multicolumn{2}{|c|}{ Mean treatment duration with BoNT-A (years) } & \multicolumn{2}{|l|}{ AbobotulinumtoxinA } \\
\hline \multicolumn{2}{|c|}{ Mean treatment duration (years) } & \multicolumn{2}{|l|}{10.309} \\
\hline \multicolumn{2}{|c|}{ Nonresponders } & \multicolumn{2}{|l|}{0.575} \\
\hline \multicolumn{2}{|l|}{ Responders } & \multicolumn{2}{|l|}{9.734} \\
\hline \multicolumn{2}{|l|}{ Cost-effectiveness results } & \multicolumn{2}{|c|}{ AbobotulinumtoxinA vs BSC without BoNT-A injections } \\
\hline \multicolumn{2}{|l|}{ Incremental QALYs gained } & \multicolumn{2}{|l|}{0.235} \\
\hline \multicolumn{2}{|c|}{ Incremental costs } & \multicolumn{2}{|l|}{$€ 7,160$} \\
\hline \multicolumn{2}{|c|}{ Incremental cost per QALY (ICER) } & \multicolumn{2}{|l|}{$£ 30,468$} \\
\hline
\end{tabular}

Abbreviations: BoNT-A, botulinum neurotoxin type A; BSC, best supportive care; ICER, incremental cost-effectiveness ratio; QALYs, quality-adjusted life-years. 
Table 2 Direct and indirect costs (please refer to Table SI for further details on the base-case model inputs)

\begin{tabular}{|c|c|c|}
\hline Costs & Details & Source/assumptions \\
\hline \multicolumn{3}{|l|}{ Direct costs } \\
\hline Drug costs & $\begin{array}{l}£ 154 \text { per } 500 \text { unit vial at initial dose } \\
\text { of BoNT-A, } 750 \text { units at subsequent } \\
\text { doses; } £ 0 \text { for BSC }\end{array}$ & $\begin{array}{l}\text { Dose varied between first injection and reinjections, as well as among } \\
\text { health states with different response levels (nonresponders and } \\
\text { responders). Model inputs for drug costs were derived from the BNF, }{ }^{34} \\
\text { the SmPC of BoNT-A products, }{ }^{27-29} \text { and expert clinical input }\end{array}$ \\
\hline Drug administration costs & $\begin{array}{l}£ \mid 46 \text { per neurologist visit for each } \\
\text { cycle of BoNT-A; } £ 0 \text { for BSC }\end{array}$ & $\begin{array}{l}\text { Incurred for each injection according to the treating health care } \\
\text { professional who administered the BoNT-A injection and the frequency } \\
\text { of treatments. Estimated using costs from the PSS, }{ }^{35} \text { frequency of visits } \\
\text { from the US ANCHOR-CD study (Ipsen Pharma, unpublished data, } \\
2012 \text { ), and UK clinical experts }\end{array}$ \\
\hline Disease management costs & $\begin{array}{l}£ \mid 38 \text { per year for BoNT-A; } £ 493 \\
\text { per year for BSC }\end{array}$ & $\begin{array}{l}\text { Hospitalizations, surgery, or health care professional visits that arise in } \\
\text { addition to BoNT-A administration visits or costs of not being treated } \\
\text { with BoNT-As. Calculated based on costs derived from Unit Costs of } \\
\text { Health and Social Care } 201 \text { I" published by PSS in the UK and "National } \\
\text { Schedule of Reference Costs Year 20I0-20I I" published by Department } \\
\text { of Health in the UK. } .^{35} \text { Frequency of disease management interventions } \\
\text { was based on consultation with clinical experts in the UK }\end{array}$ \\
\hline \multicolumn{3}{|l|}{ Indirect costs* } \\
\hline Productivity loss & $\begin{array}{l}\text { Average hourly wage was } £ 12.76 \text {. } \\
\text { Number of hours lost per week: } \\
2 \text { hours for BoNT-A; } 5 \text { hours for } \\
\text { BSC }\end{array}$ & $\begin{array}{l}\text { Indirect costs per week were estimated by multiplying the lost } \\
\text { productivity time by the average hourly income in the UK. Average } \\
\text { hourly wage was based on data from the ONS } \mathrm{ON}^{26} \text { and the number of hours } \\
\text { lost derived from published literature }\end{array}$ \\
\hline
\end{tabular}

Note: *Indirect costs are only included as part of alternative scenario analysis.

Abbreviations: ANCHOR-CD, AbobotulinumtoxinA Neurotoxin: Clinical and Health Economics Outcomes Registry in Cervical Dystonia; BNF, British National Formulary; BoNT-A, botulinum neurotoxin type A; BSC, best supportive care; ONS, Office for National Statistics; PSS, Personal Social Services; SmPC, summary of product characteristics.

\section{Resource use and cost inputs}

Direct medical costs in the model comprised the value of all goods, services, and other resources involved in providing the intervention and all current and future consequences linked to the disease process. These included primarily drug costs, administration costs, and disease management costs as outlined in Table 2 . All other resources used, concomitant medication costs, and unit costs are detailed in Table S1. In particular, the model assumed that the drug dose varied between first injection and reinjections, as well as among health states with different response levels (nonresponders and responders). Reinjections were associated with a higher dose than first injection, as real-world treatment patterns indicate that doctors normally start with the lowest dose and increase it gradually in subsequent injections if the patient does not respond. Consequently, nonresponders have a higher average dose than responders. Model inputs for first injection were obtained from the summary of product characteristics (SmPC) for each BoNT-A, ${ }^{27-29}$ while doses and treatment intervals for subsequent injections were those suggested by clinical experts.

Drug administration costs were incurred for each injection according to the health care professional who gave the BoNT-A injection and the frequency of treatments.
Concomitant medication costs were incurred for medications used by patients with CD in addition to BoNT-A therapy. Disease management costs comprised those of hospitalizations, surgery, or health care professional visits required additionally to those for BoNT-A administration.

Indirect costs primarily included costs associated with productivity losses of patients with $\mathrm{CD}$. To quantify the economic impact of productivity losses, lost productive time (LPT) from Stacy et al (2012) $)^{30}$ was used to estimate the perperson hours per week associated with reduced performance at work ("presenteeism") and absence from work ("absenteeism") due to disability. The associated indirect costs per week were estimated by multiplying the LPT by the average hourly income in the UK (given in Table S1). Due to unavailability of data, indirect costs for time to doctor office visits and for caregivers' time were not considered.

\section{Analyses \\ Base-case analysis}

The base-case analysis compared the costs and QALYs, discounted at $3.5 \%$, of using abobotulinumtoxinA versus BSC, from the NHS and PSS perspective over a lifetime horizon in a scenario where response is considered as at least $20 \%$ improvement in TWSTRS total score from 
baseline and vial-sharing was not allowed. The base-case model parameters are presented in Table S1 alongside their assumptions, with the exception of indirect costs, which were considered only in an alternative scenario analysis described ahead.

\section{Alternative scenario analysis}

Alternative scenario analyses were conducted to test the following assumptions: productivity losses incurred by patients with CD; sharing of vials; analytic time horizon of 5 years; injection cycles as in the SmPCs, specifically, 16 weeks for abobotulinumtoxin $\mathrm{A},{ }^{28} 10$ weeks for incobotulinumtoxin $\mathrm{A},{ }^{29}$ 10 weeks cycle for onabotulinumtoxin $\mathrm{A}^{27}$; at least $30 \%$ improvement in TWSTRS from baseline and allowance of secondary nonresponse following the initial BoNT-A injection, or achievement of response at subsequent injection cycles for initial nonresponders. The following comparisons were also performed: onabotulinumtoxinA versus BSC; incobotulinumtoxinA versus BSC; abobotulinumtoxinA versus onabotulinumtoxinA; and abobotulinumtoxinA versus incobotulinumtoxinA.

\section{One-way sensitivity analysis}

To identify model drivers and examine key areas of uncertainty within the model, one-way sensitivity analyses were provided for all major model variables. Parameters were varied between a minimum and maximum range that was determined directly from published data. Where data were not available to inform this range, the minimum and maximum values were $\pm 20 \%$ of the base-case value. Tornado diagrams were generated for incremental costs, incremental QALYs and ICERs, and incremental net benefit using a $£ 20,000$ / QALY threshold. Table S3 lists the parameters varied in one-way sensitivity analysis.

\section{Probabilistic sensitivity analysis}

To account for multivariate and stochastic uncertainties in the model, a probabilistic sensitivity analysis was performed. Probabilistic parameters were defined according to appropriate statistical distributions to ascertain uncertainty. The selection of distributions was dependent on the nature of the underlying parameter, with beta distribution being used for probabilities and utilities, and gamma distribution used for positively valued parameters such as the costs.

The probabilistic sensitivity analysis was run for 5,000 simulations. The incremental gains in terms of QALYs were plotted against incremental costs of abobotulinumtoxinA and its comparators on the cost-effectiveness plane. A costeffectiveness acceptability curve was generated to show the probability of being cost-effective for each treatment over a range of willingness-to-pay values for a QALY. Table S4 lists the distribution of parameters varied in probabilistic sensitivity analysis.

\section{Results}

\section{Base-case results}

The discounted costs and health outcomes for abobotulinumtoxinA and BSC for the base case are given in Table 1. The total incremental QALYs gained from abobotulinumtoxinA compared to BSC was 0.235 per patient, with the total incremental cost being $£ 7,160$. This corresponds to an ICER of $£ 30,468$ per QALY gained.

\section{Alternative scenario results}

The results of abobotulinumtoxinA versus BSC for the alternative scenarios are presented in Table 3 . With vial-sharing, the total incremental QALYs gained were unchanged but the associated total incremental costs were $£ 6,234$, corresponding to an ICER of $£ 26,526$ per QALY (i.e., lower than the base-case ICER). When productivity losses were considered, the QALYs remained unchanged but the total incremental costs were $-£ 7,311$, implying that abobotulinumtoxinA usage was cost-saving compared to BSC. Changing the time horizon to 5 years resulted in total incremental costs of $£ 2,809$, incremental QALYs of 0.083 , and an ICER of $£ 38,117$. Considering 5\% secondary nonresponders and $25 \%$ secondary responders resulted in total incremental QALYs of 0.247 , total incremental costs of $£ 10,072$, and an ICER of $£ 40,777$. With a 16 -week reinjection interval for abobotulinumtoxinA, ${ }^{28}$ the incremental costs and QALYs were found to be $£ 5,396$ and 0.252 , respectively, with an associated ICER of $£ 21,413$. Considering response as $30 \%$ improvement in TWSTRS from baseline resulted in an ICER of $£ 29,089$ (i.e., lower than the base-case ICER).

Table S5 presents comparisons of onabotulinumtoxinA and incobotulinumtoxinA versus BSC and abobotulinumtoxin $\mathrm{A}$ versus onabotulinumtoxin $\mathrm{A}$ and incobotulinumtoxin $\mathrm{A}$ for 12- and 10-week reinjection intervals. Compared to BSC, the ICERs for onabotulinumtoxinA and incobotulinumtoxinA were $£ 48,978$ and $£ 58,554$ for the 12 -week injection cycle, and $£ 48,625$ and $£ 44,933$ for the 10 -week interval, respectively, due to higher drug-acquisition costs associated with onabotulinumtoxinA and incobotulinumtoxinA compared to abobotulinumtoxinA. 
Table 3 Alternative scenario results: abobotulinumtoxinA compared to BSC

\begin{tabular}{|c|c|c|c|c|c|c|c|}
\hline \multirow[t]{2}{*}{ Scenario } & \multicolumn{2}{|c|}{ AbobotulinumtoxinA } & \multicolumn{2}{|l|}{ BSC } & \multicolumn{3}{|c|}{$\begin{array}{l}\text { Incremental } \\
\text { (AbobotulinumtoxinA vs BSC) }\end{array}$} \\
\hline & $\begin{array}{l}\text { Total costs } \\
\text { (discounted) }\end{array}$ & QALYs & $\begin{array}{l}\text { Total costs } \\
\text { (discounted) }\end{array}$ & QALYs & $\begin{array}{l}\text { Total costs } \\
\text { (discounted) }\end{array}$ & QALYs & ICERs \\
\hline Base case & $E|6,5| 7$ & 11.970 & $£ 9,357$ & 11.735 & $£ 7,160$ & 0.235 & $£ 30,468$ \\
\hline $\begin{array}{l}\text { Considering } 5 \% \text { secondary } \\
\text { nonresponders and } 25 \% \text { secondary } \\
\text { responders }\end{array}$ & $£ 19,429$ & 11.982 & $£ 9,357$ & 11.735 & $£ 10,072$ & 0.247 & $£ 40,777$ \\
\hline $\begin{array}{l}\text { Considering } 16 \text { weeks reinjection } \\
\text { interval for abobotulinumtoxinA* }\end{array}$ & $£ \mid 4,728$ & 11.948 & $£ 9,332$ & 11.696 & $£ 5,396$ & 0.252 & $£ 2 I, 4 \mid 3$ \\
\hline $\begin{array}{l}\text { Considering response as } \geq 30 \% \\
\text { improvement in TWSTRS from } \\
\text { baseline }\end{array}$ & $£ 16,222$ & 11.974 & $£ 9,357$ & 11.738 & $£ 6,865$ & 0.236 & $£ 29,089$ \\
\hline $\begin{array}{l}\text { Considering indirect costs due to } \\
\text { productivity loss }\end{array}$ & $£ 61,97 \mid$ & 11.970 & $£ 69,282$ & 11.735 & $-€ 7,311$ & 0.235 & Cost-saving \\
\hline Considering vial-sharing & $£|5,59|$ & 11.970 & $£ 9,357$ & 11.735 & $£ 6,234$ & 0.235 & $£ 26,526$ \\
\hline Time horizon $=5$ years & $£ 5,443$ & 2.942 & $£ 2,280$ & 2.859 & $£ 2,809$ & 0.083 & $£ 38,117$ \\
\hline
\end{tabular}

Note: *Same reinjection interval (16 weeks) was assumed for BSC.

Abbreviations: BSC, best supportive care; ICERs, incremental cost-effectiveness ratios; QALYs, quality-adjusted life-years; TWSTRS, Toronto Western Spasmodic Torticollis Rating Scale.

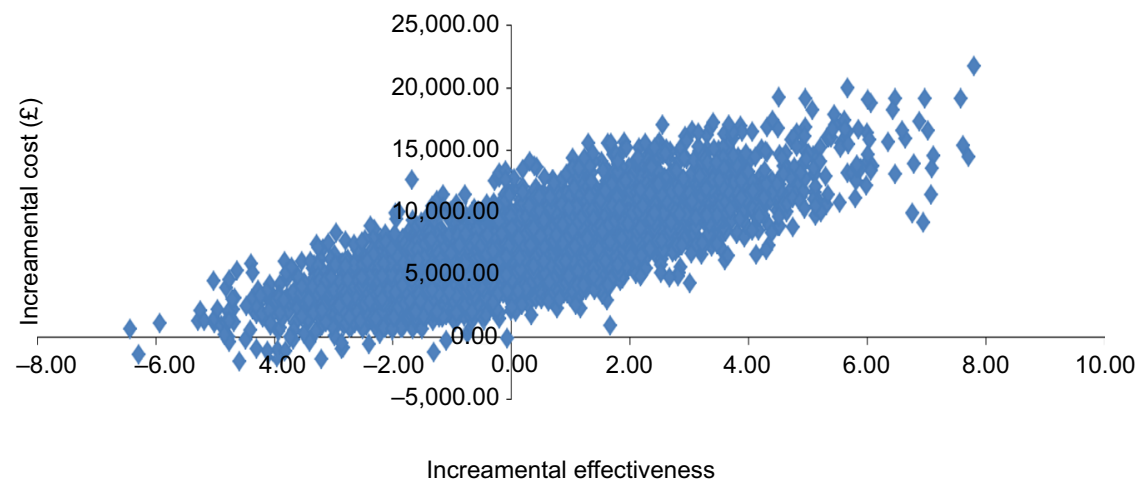

Figure 3 Cost-effectiveness planes of incremental costs per QALY of abobotulinumtoxinA versus BSC. Abbreviation: BSC, best supportive care; QALY, quality-adjusted life-year.

\section{One-way sensitivity analysis results}

One-way (deterministic) sensitivity analysis was conducted on the parameters listed in Table S3. The tornado diagrams given in Figures S2-S5 show the most influential parameters on outcomes for abobotulinumtoxinA versus BSC. Incremental costs were most influenced by the proportion of responders to abobotulinumtoxinA at first injection, duration of the reinjection interval, and the number of cycles of reinjection allowed among primary nonresponders. Incremental QALYs and incremental net benefit were most sensitive to number of cycles of reinjection allowed amongst primary nonresponders and proportion of responders and nonresponders to abobotulinumtoxinA at first injection.
ICERs were most sensitive to TWSTRS value at baseline among BSC and abobotulinumtoxinA patients and the number of cycles of reinjection allowed among primary nonresponders.

\section{Probabilistic sensitivity analysis results}

Results of the probabilistic sensitivity analysis conducted for the base case are presented in Figures 3 and 4. The costeffectiveness plane shows that, although abobotulinumtoxinA is more costly than BSC, it is also more effective. The CEAC showed that abobotulinumtoxinA had a $46 \%$ probability of being cost-effective at a threshold of $£ 20,000$ compared to BSC without BoNT-A injections. 


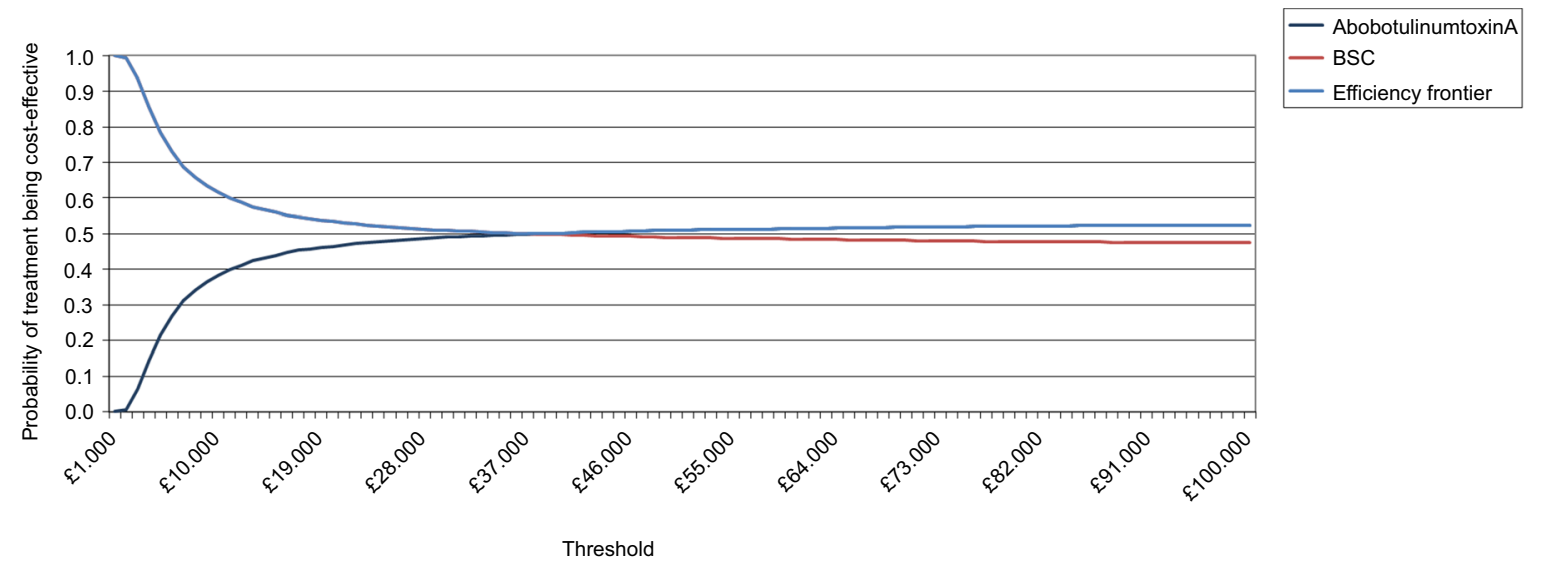

Figure 4 Cost-effectiveness acceptability curves of abobotulinumtoxinA and BSC without toxins injections. Abbreviation: BSC, best supportive care.

\section{Discussion}

Our economic model showed for patients with $\mathrm{CD}$ in the UK that abobotulinumtoxinA was cost-effective compared to BSC, at a maximum acceptable willingness-to-pay threshold of $£ 30,000$ per QALY $^{24}$ under base-case assumptions. Specifically, the treatment provided a lifetime gain of 0.235 QALYs at an incremental cost of $£ 7,160$ and the health benefits was attributable to a reduction in the severity of CD (as measured by TWSTRS, which correlated directly with patients' utility). In addition, the results remained broadly consistent in both testing of alternative scenarios to the base cases and across a range of sensitive analyses. Overall, therefore, our findings represent a significant development in the knowledge of the economic and health benefits of using BoNT-As for this indication, given that few other economic evaluations of these treatments for $\mathrm{CD}$ have been previously published. ${ }^{21,31}$

As with many models, ours had limitations arising from data availability and structural assumptions. In terms of clinical response, data were available to estimate the proportion of responders and their improvement in TWSTRS total score for the first injection cycle from clinical trial ${ }^{25}$ but not for subsequent cycles. Therefore, it was assumed that only the first injection determined response, although in clinical practice additional responses would probably be achieved in subsequent cycles for more patients. Furthermore, there was a lack of data on the quantities of abobotulinumtoxinA administered and health care resources consumed in managing patients. We made the assumption that the utilityTWSTRS relationship, which was estimated based on data from one cycle of botulinum toxin use, would apply equally to subsequent cycles, though we cannot know how this relationship may differ at later times. Having to extrapolate outcomes beyond the timeframe of available clinical data was another unavoidable limitation - one commonly encountered in this type of evaluation.

A key strength of our study is how it took account of productivity gains resulting from effective treatment for CD. The importance of CD's effect on productivity has been recognized previously, although studies have not generally quantified it suitably for subsequent use in economic evaluations. For instance, a study of almost 300 patients by the Finnish Dystonia Association ${ }^{32}$ found 97 subjects (39\%) had retired because of $\mathrm{CD}$ at a median age of 48 years, while many others reported sick leave, reduced productivity, and loss of employment. ${ }^{14,33}$ Similarly, a second study found $53.3 \%$ of patients with $\mathrm{CD}$ reported that employment status was negatively affected through reduced hours or responsibilities, including $18.9 \%$ of patients who had lost employment due to CD symptoms. ${ }^{15}$

Another reason that is essential to demonstrate the cost-effectiveness of BoNT-A is that many patients receive inappropriate treatment (e.g., physiotherapy alone), given that $\mathrm{CD}$ is an under-recognized condition and BoNT-As are consequently underutilized for $\mathrm{CD}$. To the extent that cost of treatment with BoNT-A is a potential barrier, it is important to communicate the cost-effectiveness of BoNT-A. In conclusion, we believe that in demonstrating the cost-effectiveness of abobotulinumtoxin $\mathrm{A}$ as treatment for $\mathrm{CD}$, our study makes a compelling case for wider use in the UK of such therapy that can benefit patients with this physically and psychologically debilitating condition. 


\section{Conclusion}

The use of abobotulinumtoxinA in adult patients with $\mathrm{CD}$ was found to be cost-effective at an acceptable willingnessto-pay threshold in the UK and also provided additional QoL gains. This evidence should help to inform clinical decision making and commissioning where BoNT-A therapy is being considered as a potential treatment for $\mathrm{CD}$.

\section{Acknowledgments}

This study was funded by Ipsen Pharma. An abstract of this paper was presented at the ISPOR 18th Annual European Congress, Milan, Italy, November 2015 as a poster presentation:

http://www.valueinhealthjournal.com/article/ $\underline{\text { S1098-3015(15)04544-1/abstract }}$

The poster's abstract was published in Value in Health, Volume 18, Issue 7:

Desai, K et al. AbobotulinumtoxinA In The Management of Cervical Dystonia In The United Kingdom: A CostEffectiveness Analysis. Value in Health, Volume 18, Issue 7, A757-A758.

\section{Author contributions}

All authors contributed toward data analysis, drafting and revising the paper and agree to be accountable for all aspects of the work.

\section{Disclosure}

MM, SA, and KD are employees of Evidera Inc., which received consultancy fees to conduct the research from Ipsen Pharma. JD and SG are both full-time employees of Ipsen Pharma. TH has received consultancy fees from Ipsen Pharma for work relating to Spasticity management TH has also received honoraria for lectures delivered from Merz and Allergan. Ipsen Pharma did not have any influence on the interpretation of data as well as the final conclusions drawn. The authors report no other conflicts of interest in this work.

\section{References}

1. Lalli S, Albanese A. The diagnostic challenge of primarydystonia: evidence from misdiagnosis. Mov Disord. 2010;25(11):1619-1626.

2. Albanese A, Asmus F, Bhatia KP, et al. EFNS guidelines on diagnosis and treatment of primary dystonias. Eur J Neurol. 2011;18(1):5-18.

3. Bloudek LM, Stacy M, Schwartz M, Brin M, Papapetropoulos S. Cost of cervical dystonia in the United States [abstract]. Mov Disord. 2012;15(4):A142-A413.

4. Coelho M, Valadas AF, Mestre T, Ferreira JJ. Pain and quality of life in the treatment of cervical dystonia. Eur Neurol Rev. 2009;4(2):74-78.

5. Marras C, Van den Eeden SK, Fross RD, et al. Minimum incidence of primary cervical dystonia in a multiethnic health care population. Neurology. 2007;69(7):676-680.

6. Warner T, Camfield L, Marsden C, et al. A prevalence study of primary dystonia in eight European countries. J Neurol. 2000;247(10):787-792.
7. Nutt JG, Muenter MD, Aronson A, Kurland LT, Melton LJ 3rd. Epidemiology of focal and generalised dystonia in Rochester, Minnesota. Mov Disord. 1988;3(3):188-194.

8. Abogunrin S, Brand S, Desai K, Dinet J, Gabriel S, Harrower T. AbobotulinumtoxinA in the management of cervical dystonia in the United Kingdom: a budget impact analysis. Clinicoecon Outcomes Res 2015;7:441-449.

9. Dystonia - NHS Choices. Available from: http://www.nhs.uk/conditions/ dystonia/pages/introduction.aspx. Accessed July 22, 2016.

10. Zoons E, Dijkgraaf MG, Dijk JM, van Schaik IN, Tijssen MA. Botulinum toxin as treatment for focal dystonia: a systematic review of the pharmaco-therapeutic and pharmaco-economic value. J Neurol. 2012;259(12):2519-2526.

11. Walker FO. Botulinum toxin therapy for cervical dystonia. Phys Med Rehabil Clin. 2003;14(4):749-766.

12. David M. Simpson, Mark Hallett, Eric J. Ashman, et al. Practice guideline update summary: botulinum neurotoxin for the treatment of blepharospasm, cervical dystonia, adult spasticity, and headache. Neurology. 2016;86(19):1818-1826.

13. Hilker R, Schischniaschvili M, Ghaemi M, Jacobs A, Rudolf J. Health related quality of life is improved by botulinum neurotoxin type A in long term treated patients with focal dystonia. J Neurol Neurosurg Psychiatry. 2001;71(2):193-199.

14. Skogseid IM, Røislien J, Claussen B, Kerty E. Long-term botulinum toxin treatment increases employment rate in patients with cervical dystonia. Mov Disord. 2005;20(12):1604-1609.

15. Molho ES, Agarwal N, Regan K, Higgins DS, Factor SA. Effect of cervical dystonia on employment: a retrospective analysis of the ability of treatment to restore premorbid employment status. Mov Disord. 2009;24(9):1384-1387.

16. Comella CL, Jankovic J, Shannon KM, Tsui J, Swenson M, Leurgans S, Fan W; Dystonia Study Group. Comparison of botulinum toxin serotyopes A and B for the treatment of cervical dystonia. Neurology. 2005;65(9):1423-1429.

17. Consky E, Basinski A, Belle L, Ranawaya R, Lang AE. The Toronto Western Spasmodic Torticollis Rating Scale (TWSTRS): assessment of validity and inter-rater reliability [abstract]. Neurology. 1990;40(Suppl 1):445.

18. Han Y, Stevens A, Dashtipour K, Hauser R, Mari Z. A mixed treatment comparison (MTC) to compare the efficacy of botulinum toxin type A treatments for cervical dystonia. Value Health. 2014;17(3):A57.

19. Han Y, Stevens A, Dashtipour K, Hauser RA, Mari Z. A mixed treatment comparison to compare the efficacy and safety of botulinum toxin treatments for cervical dystonia. J Neurol. 2016;263(4):772-780.

20. Brockmann K, Schweitzer K, Beck G, Wächter T. Comparison of different preparations of botulinumtoxin $\mathrm{A}$ in the treatment of cervical dystonia. Neurol Asia. 2012;17(2):115-119.

21. Kazerooni R, Broadhead C. Cost-utility analysis of botulinum toxin type A products for the treatment of cervical dystonia. Am J Health Syst Pharm. 2015;72(4):301-307.

22. Sonnenberg FA, Beck JR. Markov models in medical decision making: a practical guide. Med Decis Making. 1993;13(4):322-338.

23. Briggs A, Sculpher M. An introduction to Markov modelling for economic evaluation. Pharmacoeconomics. 1998;13(4):397-409.

24. National Institute for Health and Care Excellence (NICE). Guide to the methods of technology appraisal. 2013. NICE article [PMG9]. London: NICE. Avaliable from: http://publication.nice.org.uk/pmg9. Accessed January 2016.

25. Truong D, Brodsky M, Lew M, et al; Global dysport cervical dystonia study group. Long-term efficacy and safety of botulinum toxin type A (Dysport) in cervical dystonia. Parkinsonism Relat Disord. 2010;16(5):316-323.

26. Office for national statistics (ONS). Annual Survey of Hours and Earnings, 2013 Provisional Results; 2013. Available from: http://www.ons. gov.uk/ons/dcp171778_335027.pdf. Accessed January 2016.

27. Electronic Medicines Compendium (eMC). Bortox $₫ 100$ units, Bortox ${ }^{\circledR}$ 50 units, Summary of Product Characteristics.Available from: https:// www.medicines.org.uk/emc/medicine/112; https://www.medicines. org.uk/emc/medicine/22562; https://www.medicines.org.uk/emc/ medicine/20564. Accessed January 2016. 
28. Electronic medicines compendium (eMC). Dysport ${ }^{\circledR} 300$ units, Dysport ${ }^{\circledR}$ 500 units, summary of product characteristics. Available from: https:// www.medicines.org.uk/emc/medicine/870. Accessed January 2016.

29. Electronic medicines compendium (eMC). Xeomin ${ }^{\circledR} 100$ units, Xeo$\min { }^{\circledR} 50$ units, summary of product characteristics. Available from: https://www.medicines.org.uk/emc/medicine/20666; https://www. medicines.org.uk/emc/medicine/24582. Accessed January 2016.

30. Stacy M, Bloudek L, Schwartz M, Brin M, Papapetropoulos S. Cervical dystonia substantially impacts employment status, absenteeism, and presenteeism: Baseline results from cervical dystonia patient registry for the observation of onabotulinumtoxinA efficacy (CD PROBE). Mov Disord. 2012(27):1106.

31. Tilden D, Guarnieri C. Cost-Effectiveness of incobotulinumtoxin-A with flexible treatment intervals compared to onabotulinumtoxin-A in the management of blepharospasm and cervical dystonia. Value Health. 2016;19(2):145-152.
32. Martikainen KK, Luukkaala TH, Marttila RJ. Working capacity and cervical dystonia. Parkinsonism Relat Disord. 2010;16(3): 215-217.

33. Burbaud P, Ducerf C, Cugy E, et al. Botulinum toxin treatment in neurological practice: how much does it really cost? A prospective cost-effectiveness study. J Neurol. 2011;258(9):1670-1675.

34. BNF: joint formulary committee. British national formulary (online); 2012. Available from: http://www.medicinescomplete.com. Accessed December, 2012.

35. PSS. Unit costs of health and social care 2011. and National Schedule of Reference Costs Year 2010-2011.Personal social services research unit (PSS); 2015. Available from: http://www.pssru.ac.uk. Accessed January 2016

36. Kessler KR, Skutta M, Benecke R. Long-term treatment of cervical dystonia with botulinum toxin A: efficacy, safety, and antibody frequency. German Dystonia study group. J Neurol. 1999;246(4):265-274. 


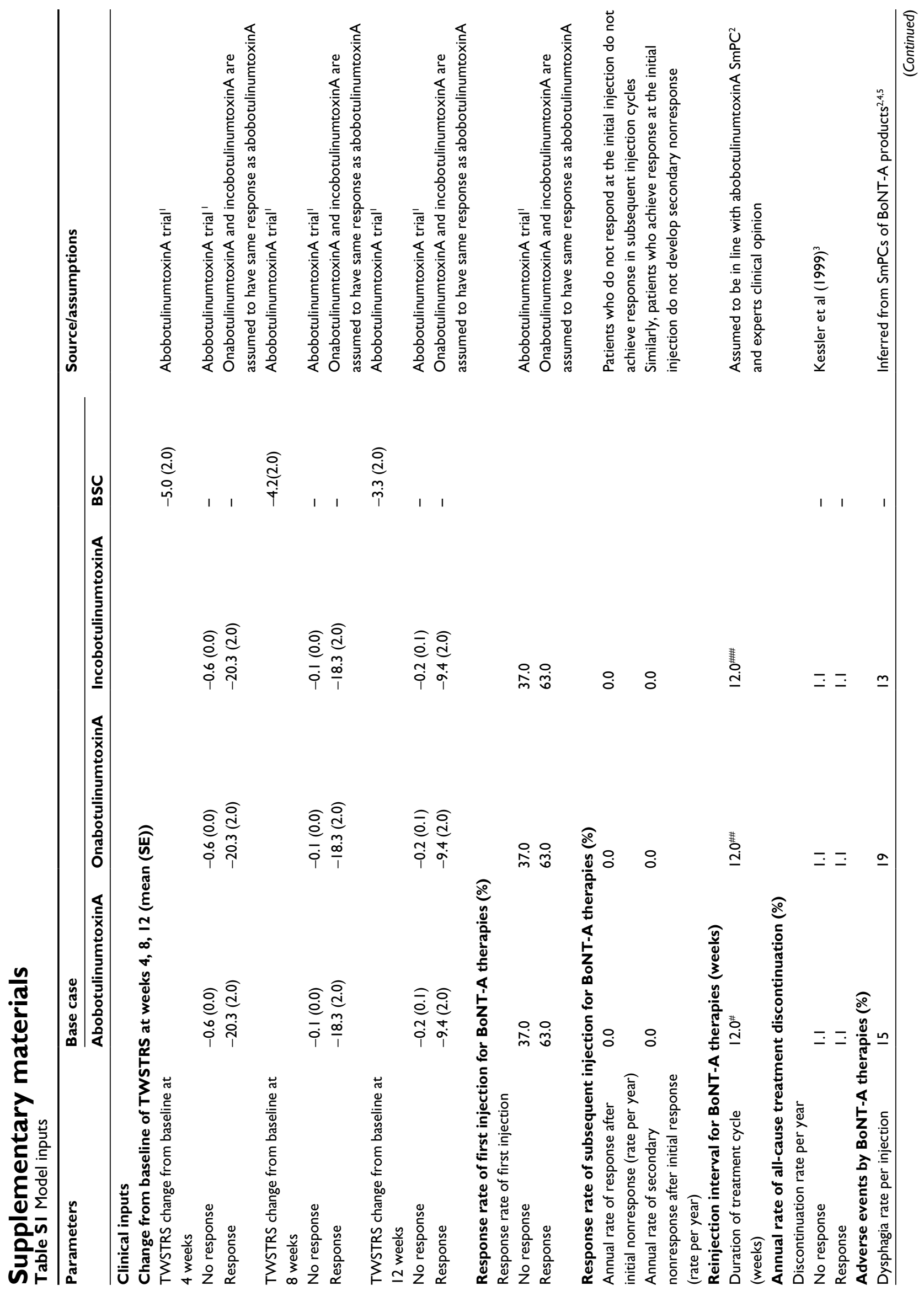




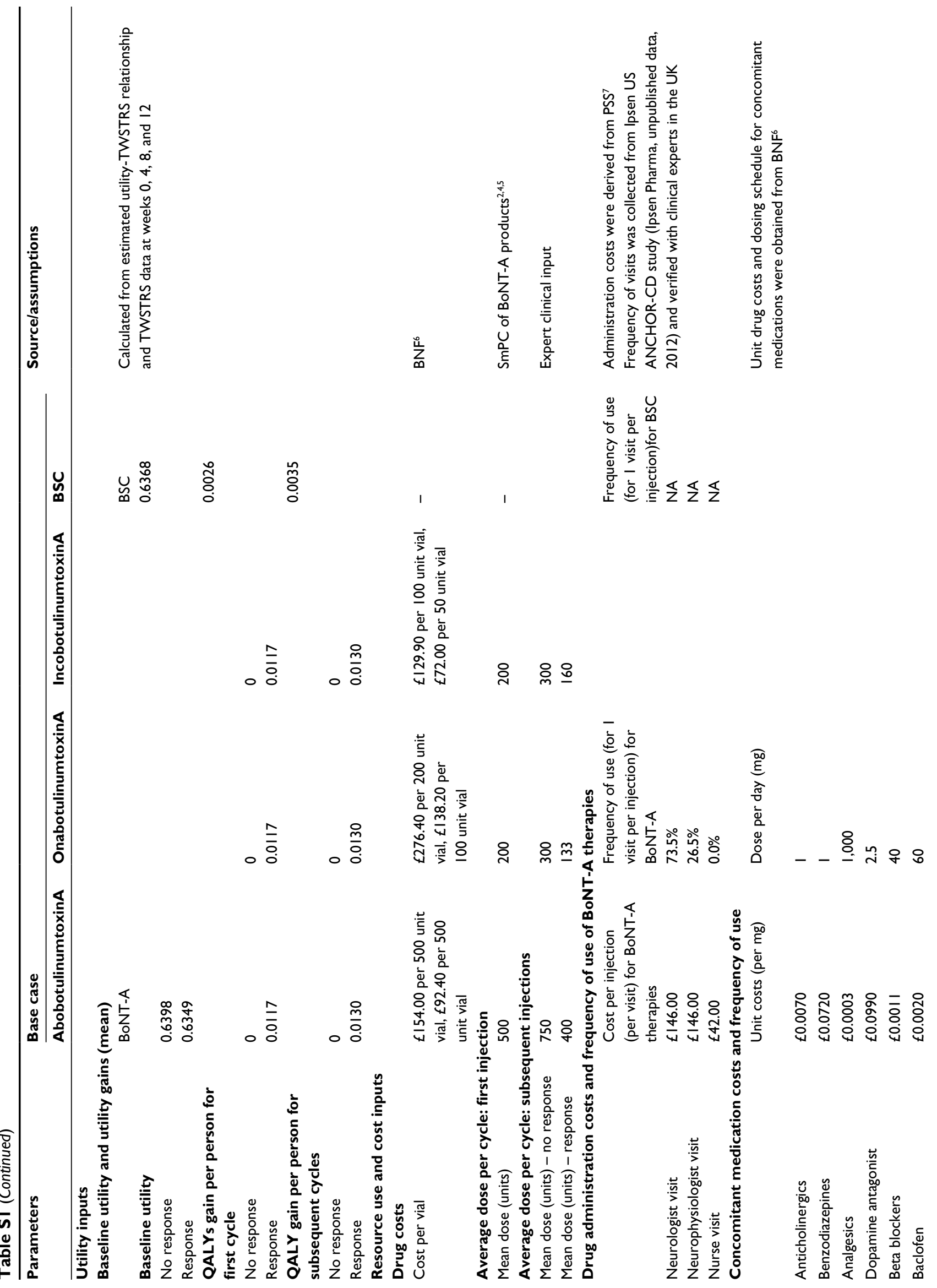



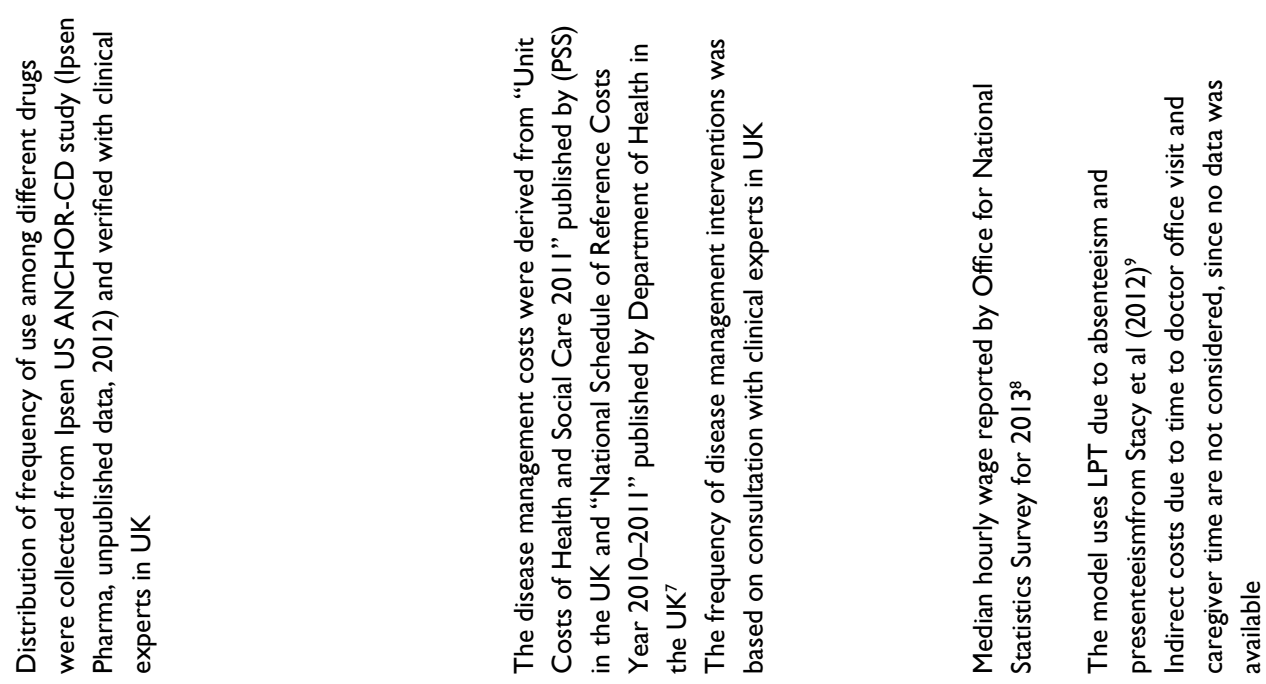

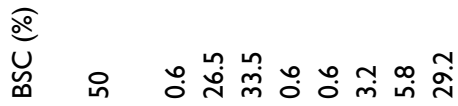

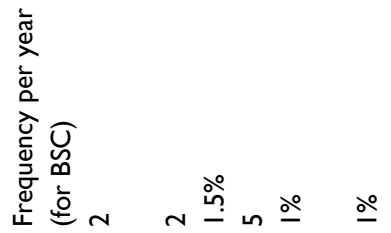

\& ำ

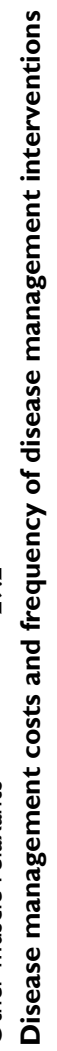

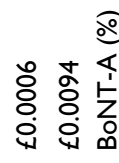

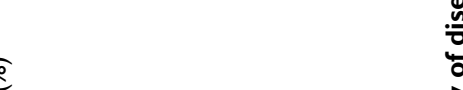

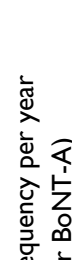

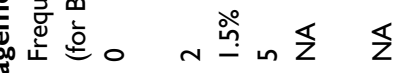

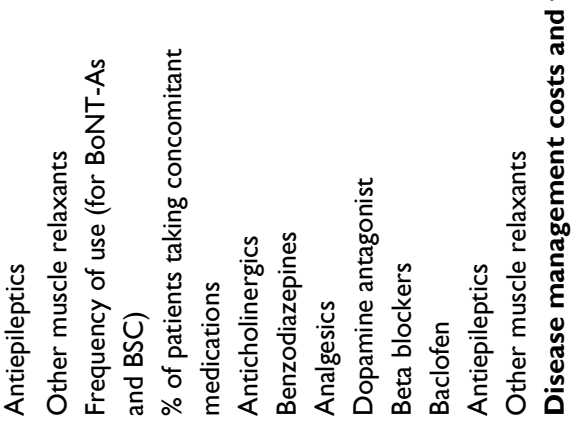

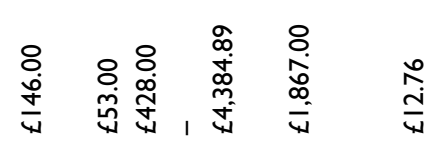
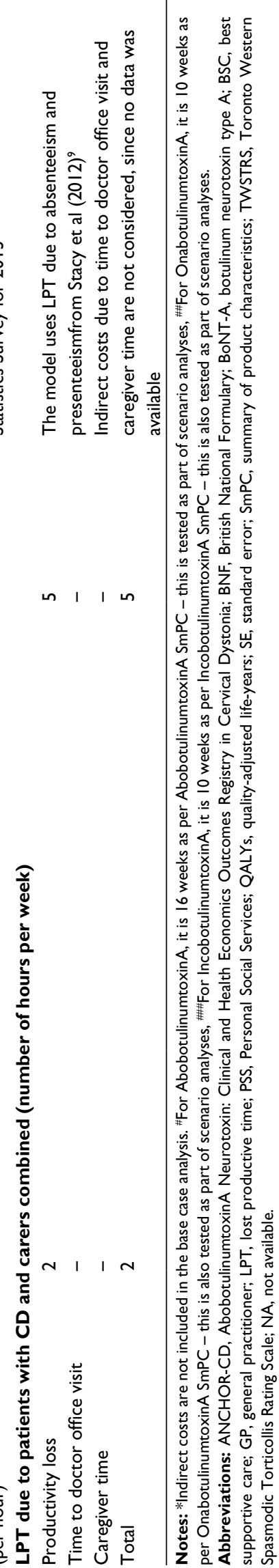
Table S2 Estimates of statistical model linking utility and TWSTRS based on analysis of abobotulinumtoxinA trial

\begin{tabular}{lll}
\hline Parameter & $\begin{array}{l}\text { Parameter } \\
\text { estimate }\end{array}$ & Parameter \\
\hline $\begin{array}{l}\text { Intercept } \\
\text { Coefficient for }\end{array}$ & $\begin{array}{l}1.255 \\
-0.0159\end{array}$ & \\
TWSTRS & $\begin{array}{l}\text { Covariance } \\
\text { matrix } \\
\text { Intercept }\end{array}$ & $\begin{array}{l}\text { Coefficient } \\
\text { for TWSTRS }\end{array}$ \\
Intercept & $\begin{array}{l}0.01157 \\
\text { Coefficient for TWSTRS }\end{array}$ & -0.000234 \\
\hline
\end{tabular}

Abbreviations: TWSTRS, Toronto Western Spasmodic Torticollis Rating Scale.

Table S3 Parameters included in one-way sensitivity analysis

\begin{tabular}{|c|c|c|c|c|}
\hline Parameter/variable name & Description & Base-case input & Low value & High value \\
\hline disch & Discount rate for health (\%) & 0.035 & 0.028 & 0.042 \\
\hline $\operatorname{disc} C$ & Discount rate for cost (\%) & 0.035 & 0.028 & 0.042 \\
\hline iAge & Age (years) & 53.00 & 42.400 & 63.600 \\
\hline pMale & Gender $(\%$ male $)$ & 0.37 & 0.296 & 0.444 \\
\hline TWSBline_NonResp & $\begin{array}{l}\text { Mean baseline TWSTRS - nonresponders: } \\
\text { abobotulinumtoxinA }\end{array}$ & 42.79 & 34.232 & 51.348 \\
\hline TWSBline_Resp & $\begin{array}{l}\text { Mean baseline TWSTRS - responders: } \\
\text { abobotulinumtoxinA }\end{array}$ & 44.12 & 35.296 & 52.944 \\
\hline TWSBline_BSC & Mean baseline TWSTRS - BSC & 43.63 & 34.902 & 52.353 \\
\hline Coeff_TWS & Coefficient for TWSTRS & -0.02 & -0.019 & -0.013 \\
\hline Coeff_Inter & Intercept & 1.26 & 1.004 & 1.506 \\
\hline ¡Reinj_PriNonResp & $\begin{array}{l}\text { Number of reinjection attempts for primary } \\
\text { nonresponders before abandoning treatment }\end{array}$ & 6.00 & 4.800 & 7.200 \\
\hline iReinj_SecNonResp & $\begin{array}{l}\text { Number of reinjection attempts for secondary } \\
\text { nonresponders before abandoning treatment }\end{array}$ & 4.00 & 3.200 & 4.800 \\
\hline $\begin{array}{l}\text { TWSChangeAt4Wks_Abo_ } \\
\text { nonresponder }\end{array}$ & $\begin{array}{l}\text { AbobotulinumtoxinA_TWSTRS change from } \\
\text { baseline at } 4 \text { weeks }- \text { nonresponders }\end{array}$ & -0.61 & -0.643 & -0.583 \\
\hline $\begin{array}{l}\text { TWSChangeAt4Wks_Abo_ } \\
\text { fullresponder }\end{array}$ & $\begin{array}{l}\text { AbobotulinumtoxinA_TWSTRS change from } \\
\text { baseline at } 4 \text { weeks - responders }\end{array}$ & -20.29 & -22.290 & -18.290 \\
\hline $\begin{array}{l}\text { TWSChangeAt8Wks_Abo_ } \\
\text { nonresponder }\end{array}$ & $\begin{array}{l}\text { AbobotulinumtoxinA_TWSTRS change from } \\
\text { baseline at } 8 \text { weeks - nonresponders }\end{array}$ & -0.14 & -0.140 & -0.136 \\
\hline $\begin{array}{l}\text { TWSChangeAt8Wks_Abo_ } \\
\text { responder }\end{array}$ & $\begin{array}{l}\text { AbobotulinumtoxinA_TWSTRS change from } \\
\text { baseline at } 8 \text { weeks - responders }\end{array}$ & -18.30 & -20.300 & -16.300 \\
\hline $\begin{array}{l}\text { TWSChangeAt I2Wks_Abo_ } \\
\text { nonresponder }\end{array}$ & $\begin{array}{l}\text { AbobotulinumtoxinA_TWSTRS change from } \\
\text { baseline at } 12 \text { weeks - nonresponders }\end{array}$ & -0.21 & -0.283 & -0.143 \\
\hline $\begin{array}{l}\text { TWSChangeAt I2Wks_Abo_ } \\
\text { fullresponder }\end{array}$ & $\begin{array}{l}\text { AbobotulinumtoxinA_TWSTRS change from } \\
\text { baseline at } 12 \text { weeks - responders }\end{array}$ & -9.35 & -11.350 & -7.350 \\
\hline TWSChangeAt4Wks_BSC & BSC_TWSTRS change from baseline at 4 weeks & -4.97 & -6.970 & -2.970 \\
\hline TWSChangeAt8Wks_BSC & BSC_TWSTRS change from baseline at 8 weeks & -4.22 & -6.220 & -2.220 \\
\hline TWSChangeAt I2Wks_BSC & $\begin{array}{l}\text { BSC_TWSTRS change from baseline at } 12 \\
\text { weeks }\end{array}$ & -3.32 & -5.320 & -1.320 \\
\hline $\begin{array}{l}\text { distriFirstlnj_Abo_ } \\
\text { nonresponder }\end{array}$ & Probability of nonresponse at first injection & 0.37 & 0.296 & 0.444 \\
\hline distriFirstlnj_Abo_responder & Probability of response at first injection & 0.63 & 0.504 & 0.756 \\
\hline pAE_Abo & AE rate per injection: abobotulinumtoxinA (\%) & $15 \%$ & $12 \%$ & $18 \%$ \\
\hline dFirstlnj_Abo & $\begin{array}{l}\text { AbobotulinumtoxinA_first injection dosage: } \\
\text { mean dose (unit) }\end{array}$ & 500.00 & 400.000 & 600.000 \\
\hline dFirstlnj_Ona & $\begin{array}{l}\text { OnabotulinumtoxinA_first injection dosage: } \\
\text { mean dose (unit) }\end{array}$ & 200.00 & 160.000 & 240.000 \\
\hline dFirstInj_Inco & $\begin{array}{l}\text { IncobotulinumtoxinA_first injection dosage: } \\
\text { Mean dose (unit) }\end{array}$ & 200.00 & 160.000 & 240.000 \\
\hline dReinj_Abo_nonresponder & $\begin{array}{l}\text { Average abobotulinumtoxinA reinjection } \\
\text { dosage: nonresponder (unit) }\end{array}$ & 750.00 & 600.000 & 900.000 \\
\hline
\end{tabular}




\begin{tabular}{|c|c|c|c|c|}
\hline Parameter/variable name & Description & Base-case input & Low value & High value \\
\hline dReinj_Abo_responder & $\begin{array}{l}\text { Average abobotulinumtoxinA reinjection } \\
\text { dosage: responder (unit) }\end{array}$ & 400.00 & 320.000 & 480.000 \\
\hline cDrugFirstlnj_Abo & AbobotulinumtoxinA_first injection cost $(t)$ & 154.00 & 123.200 & 184.800 \\
\hline $\begin{array}{l}\text { cDrugReinj_Abo_ } \\
\text { nonresponder }\end{array}$ & $\begin{array}{l}\text { AbobotulinumtoxinA_reinjections cost - } \\
\text { nonresponder }(t)\end{array}$ & 246.40 & 197.120 & 295.680 \\
\hline $\begin{array}{l}\text { cDrugReinj_Abo_ } \\
\text { fullresponder }\end{array}$ & $\begin{array}{l}\text { AbobotulinumtoxinA_reinjections cost - } \\
\text { responder }(t)\end{array}$ & 154.00 & 123.200 & 184.800 \\
\hline cConMed_BoNTA & Concomitant Meds Cost_BoNTA $(\ell)$ & 0.05 & 0.042 & 0.062 \\
\hline cConMed_BSC & Concomitant Meds Cost_BSC $(t)$ & 0.07 & 0.059 & 0.089 \\
\hline cDrugAdmin & Cost Drug Admin $(€)$ & 146.00 & 116.800 & 175.200 \\
\hline cDisMgt_Abo & $\begin{array}{l}\text { Cost Disease Management_ } \\
\text { AbobotulinumtoxinA }(t)\end{array}$ & 31.77 & 25.419 & 38.129 \\
\hline cDisMgt_BSC & Cost Disease Management_BSC $(t)$ & $|13.3|$ & 90.645 & 135.967 \\
\hline $\mathrm{cAE}$ & Cost AEs_BoNTA $(t)$ & - & - & - \\
\hline clndirect_BoNTA & Cost Indirect_Abo $(t)$ & 306.24 & 244.992 & 367.488 \\
\hline clndirect_BSC & Cost Indirect_BSC $(£)$ & 765.60 & 612.480 & 918.720 \\
\hline timeYearsInCycle_Abo & Reinjection Interval (years) & 0.23 & 0.184 & 0.276 \\
\hline
\end{tabular}

Abbreviations: AE, adverse event; BoNTA, botulinum neurotoxin type A; BSC, best supportive care; TWSTRS, Toronto Western Spasmodic Torticollis Rating Scale.

Table S4 Parameters included in probabilistic sensitivity analysis

\begin{tabular}{|c|c|}
\hline Parameter & Distribution \\
\hline Utility at each TWSTRS score (based on mapping) & $\begin{array}{l}\text { Multivariate } \\
\text { normal (Cholesky) }\end{array}$ \\
\hline $\begin{array}{l}\text { Mean baseline TWSTRS distribution, } \\
\text { nonresponders and responders at } 0,4,8 \text {, } \\
12 \text { weeks }\end{array}$ & Gamma \\
\hline $\begin{array}{l}\text { Transition probability: response to secondary } \\
\text { nonresponse }\end{array}$ & Beta \\
\hline Duration of treatment cycle: abobotulinumtoxinA & Gamma \\
\hline Treatment discontinuation rate per year & Gamma \\
\hline AbobotulinumtoxinA_first injection dosage & Gamma \\
\hline $\begin{array}{l}\text { AbobotulinumtoxinA_reinjection dosage: } \\
\text { nonresponder }\end{array}$ & Gamma \\
\hline $\begin{array}{l}\text { AbobotulinumtoxinA_reinjection dosage: } \\
\text { responder }\end{array}$ & Gamma \\
\hline \multicolumn{2}{|l|}{ Setting where drug is administered (distribution) } \\
\hline Neurologist visit & Beta \\
\hline Physiotherapist visit & Beta \\
\hline Nurse visit & Beta \\
\hline \multicolumn{2}{|l|}{ Disease management } \\
\hline $\begin{array}{l}\text { Neurologist visit (excluding BoNT-A injection) } \\
\text { per year }\end{array}$ & Gamma \\
\hline GP visit per year & Gamma \\
\hline Hospitalization rate per year: BoNT-A & Beta \\
\hline Hospitalization rate per year: BSC & Beta \\
\hline Length of stay for hospitalization: BoNT-A & Gamma \\
\hline Length of stay for hospitalization: BSC & Gamma \\
\hline
\end{tabular}

Abbreviations: BSC, best supportive care; BoNT-A, botulinum neurotoxin type A; GP, general practitioner; TWSTRS, Toronto Western Spasmodic Torticollis Rating Scale. 
Table S5 Alternative scenario results: other comparisons

\begin{tabular}{|c|c|c|c|c|c|c|c|}
\hline \multirow[t]{2}{*}{ Scenario } & \multicolumn{2}{|c|}{ OnabotulinumtoxinA } & \multicolumn{2}{|l|}{ BSC } & \multicolumn{3}{|c|}{$\begin{array}{l}\text { Incremental } \\
\text { (onabotulinumtoxinA vs BSC) }\end{array}$} \\
\hline & $\begin{array}{l}\text { Total costs } \\
\text { (discounted) }\end{array}$ & QALYs & $\begin{array}{l}\text { Total costs } \\
\text { (discounted) }\end{array}$ & QALYs & $\begin{array}{l}\text { Total costs } \\
\text { (discounted) }\end{array}$ & QALYs & ICERs \\
\hline Base case & $£ 20,573$ & II.964 & $£ 9,357$ & II.735 & $£|I, 2| 6$ & 0.229 & $£ 48,978$ \\
\hline $\begin{array}{l}\text { Considering } 10 \text { weeks } \\
\text { reinjection interval for } \\
\text { onabotulinumtoxinA* }\end{array}$ & $£ 21,968$ & I I.954 & $£ 9,277$ & I I.693 & $£|2,69|$ & 0.261 & $£ 48,625$ \\
\hline \multirow[t]{2}{*}{ Scenario } & \multicolumn{2}{|c|}{ IncobotulinumtoxinA } & \multicolumn{2}{|l|}{ BSC } & \multicolumn{3}{|c|}{$\begin{array}{l}\text { Incremental } \\
\text { (IncobotulinumtoxinA vs BSC) }\end{array}$} \\
\hline & $\begin{array}{l}\text { Total costs } \\
\text { (discounted) }\end{array}$ & QALYs & $\begin{array}{l}\text { Total costs } \\
\text { (discounted) }\end{array}$ & QALYs & $\begin{array}{l}\text { Total costs } \\
\text { (discounted) }\end{array}$ & QALYs & ICERs \\
\hline Base case & $£ 22,473$ & 11.959 & $£ 9,357$ & II.735 & $£ 13,116$ & 0.224 & $£ 58,554$ \\
\hline $\begin{array}{l}\text { Considering } 10 \text { weeks } \\
\text { reinjection interval for } \\
\text { incobotulinumtoxinA* }\end{array}$ & $£ 21,364$ & 11.962 & $£ 9,277$ & II.693 & $£ \mid 2,087$ & 0.269 & $£ 44,933$ \\
\hline
\end{tabular}

Note: *Same reinjection interval (10 weeks) was assumed for BSC.

Abbreviations: BSC, best supportive care; ICERs, incremental cost-effectiveness ratios; QALYs, quality-adjusted life-years.
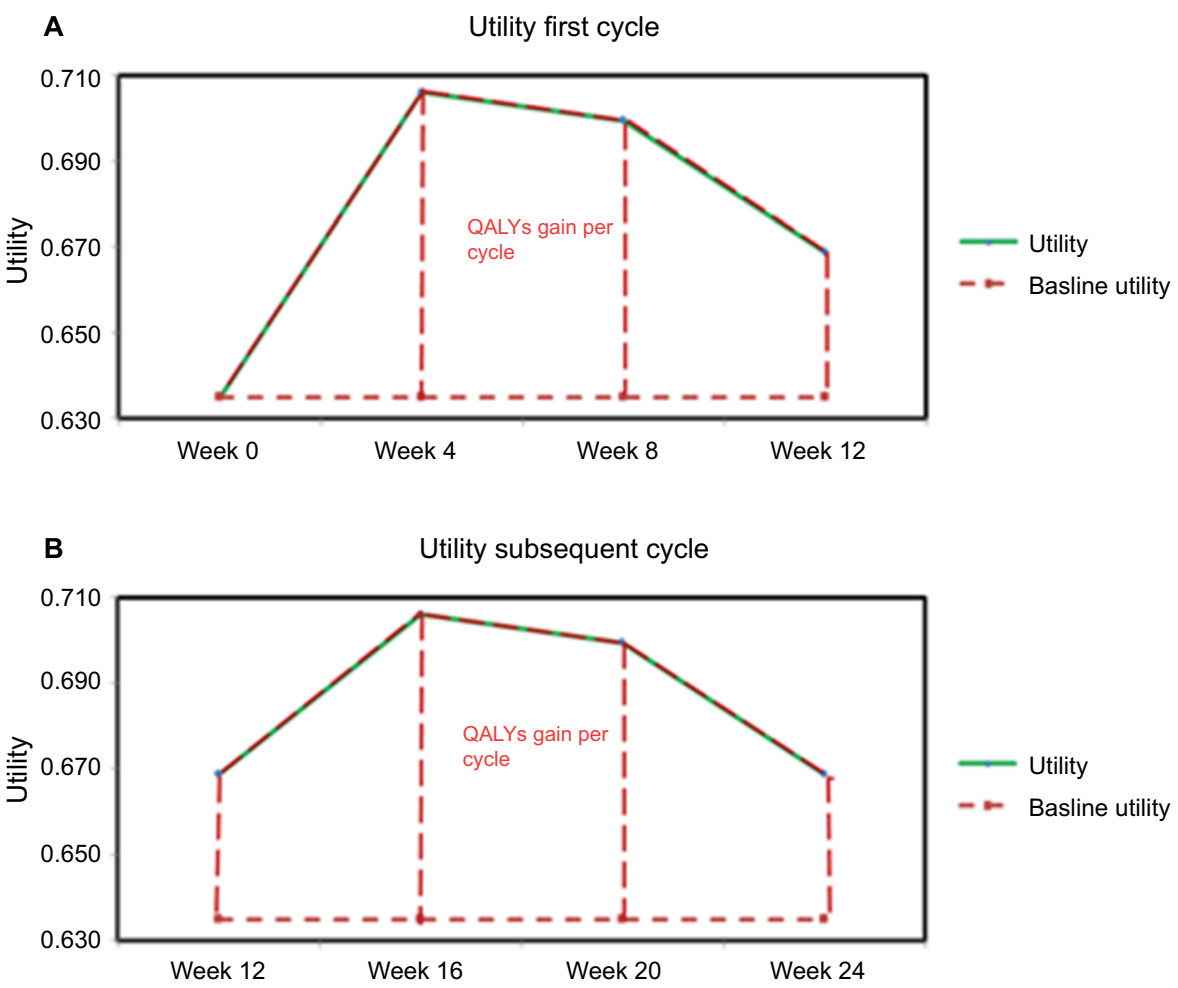

Figure SI Illustration of QALY gain in first (A) and subsequent cycle (B) when TWSTRS is assumed to have residual benefit at week 12 . Abbreviations: QALYs, quality-adjusted life-years; TWSTRS, Toronto Western Spasmodic Torticollis Rating Scale. 


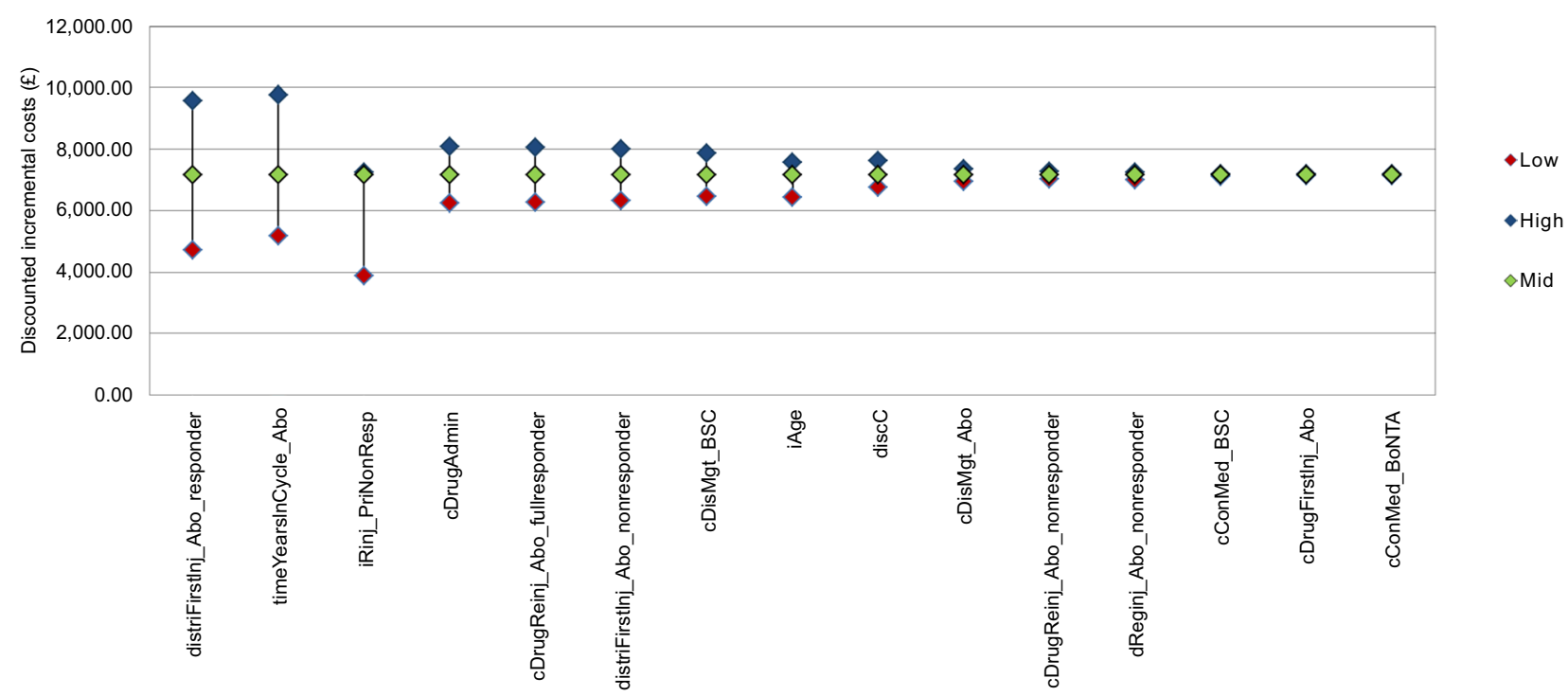

Figure S2 Tornado diagram of one-way sensitivity analysis on incremental cost.

Abbreviations: BSC, best supportive care; BoNT-A, botulinum neurotoxin type A.

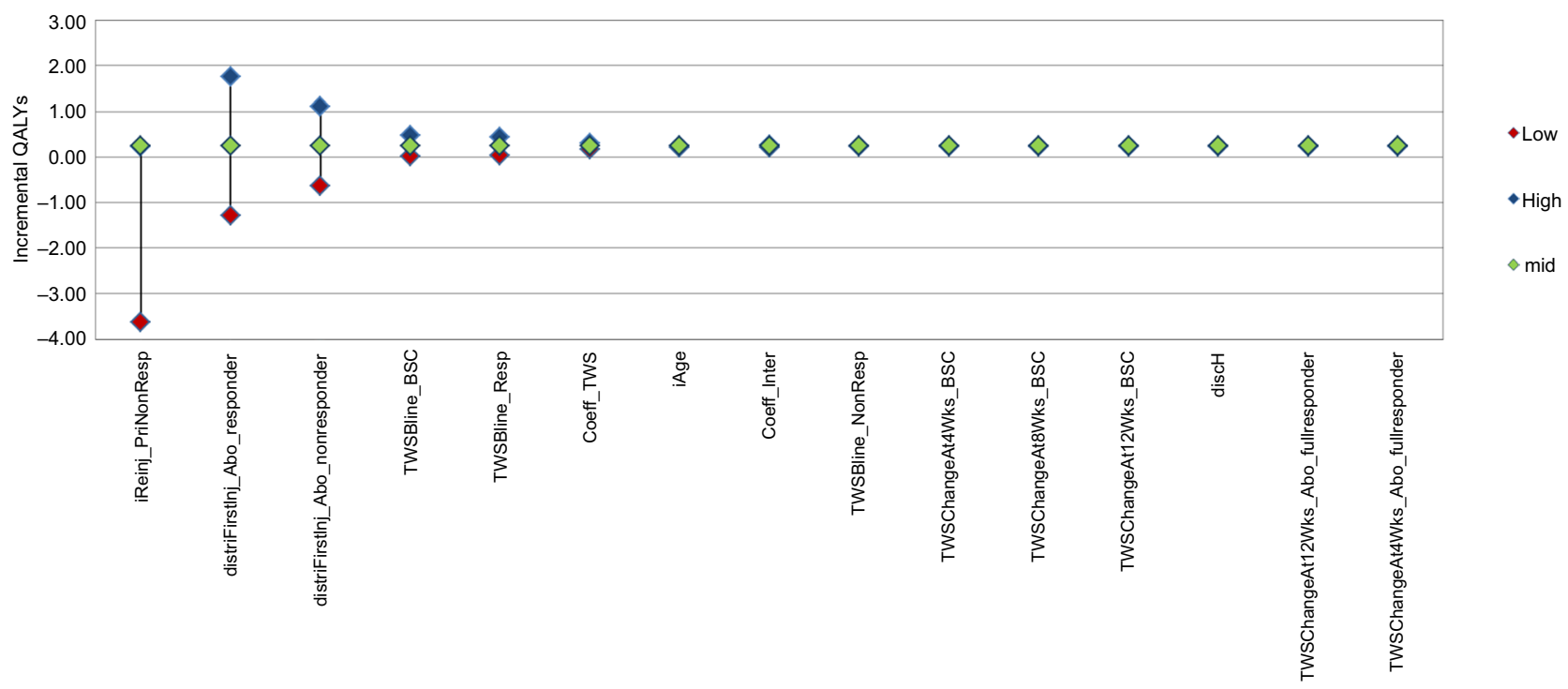

Figure S3 Tornado diagram of one-way sensitivity analysis on incremental benefit.

Abbreviations: BSC, best supportive care; QALY, quality-adjusted life-year; TWS, Toronto Western Spasmodic. 


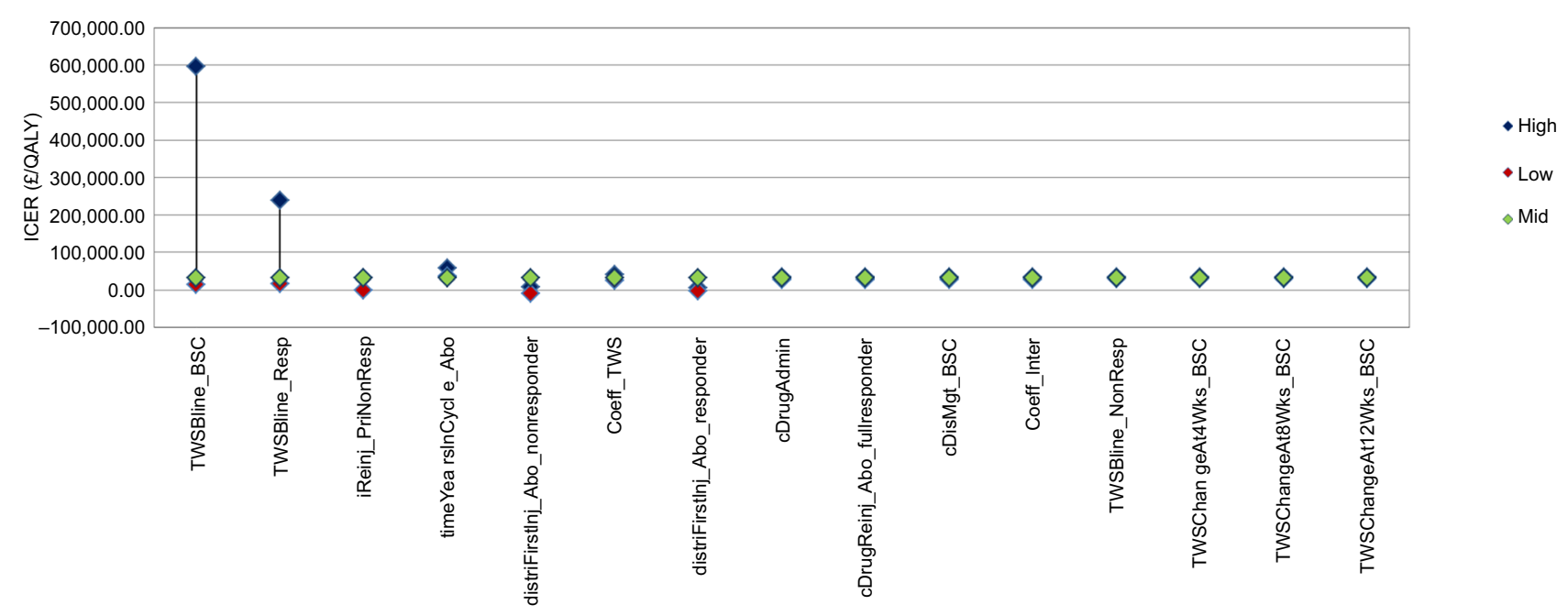

Figure S4 Tornado diagram of one-way sensitivity analysis on ICER.

Abbreviations: BSC, best supportive care; ICER, incremental cost-effectiveness ratio; TWS, Toronto Western Spasmodic.

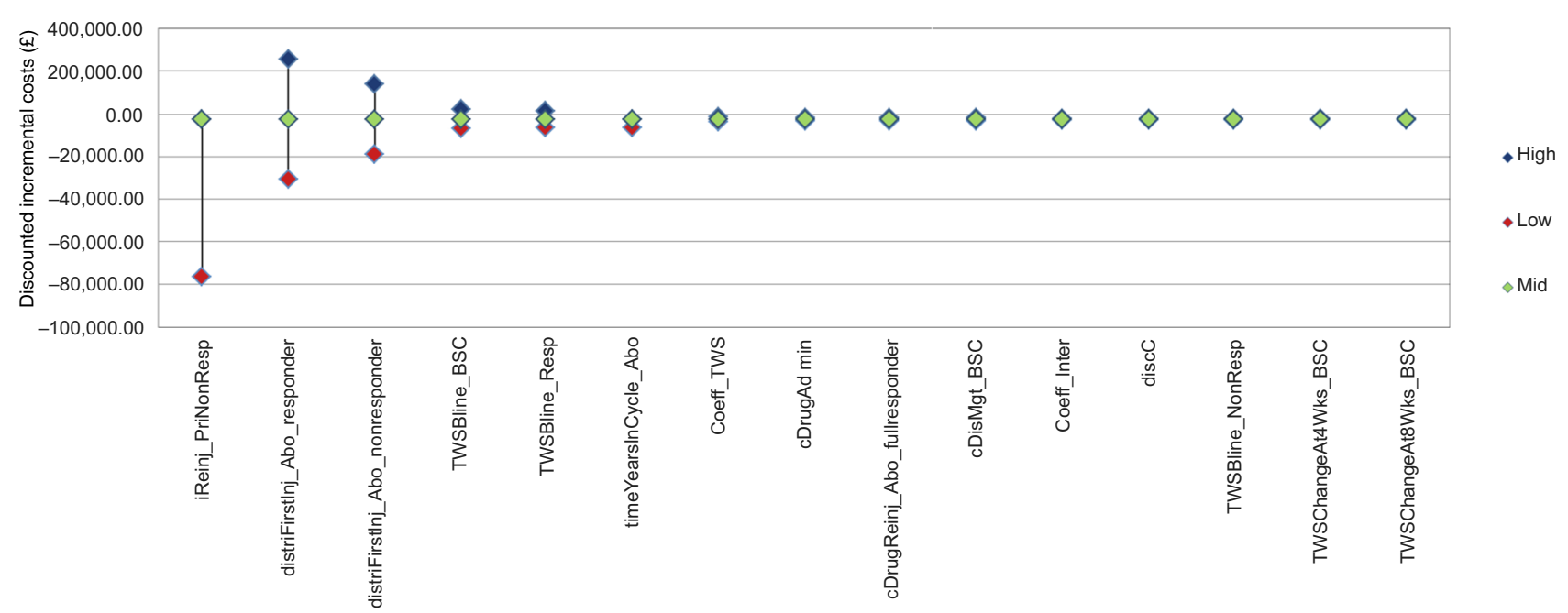

Figure S5 Tornado diagram of one-way sensitivity analysis on incremental net benefit with a willingness-to-pay threshold of $£ 20,000 / Q A L Y$.

Abbreviations: BSC, best supportive care; INB, incremental net benefit; QALY, quality-adjusted life-year; TWS, Toronto Western Spasmodic.

\section{References}

1. Truong D, Brodsky M, Lew M, et al; Global dysport cervical dystonia study group. Long-term efficacy and safety of botulinum toxin type A (Dysport) in cervical dystonia. Parkinsonism Relat Disord. 2010; 16(5):316-323.

2. Electronic medicines compendium (eMC). Dysport ${ }^{\circledR} 300$ units, Dysport ${ }^{\circledR} 500$ units, summary of product characteristics. Available from: https://www.medicines.org.uk/emc/medicine/870. Accessed January 2016.

3. Kessler KR, Skutta M, Benecke R. Long-term treatment of cervical dystonia with botulinum toxin A: efficacy, safety, and antibody frequency. German Dystonia study group. J Neurol. 1999;246(4): 265-274.

4. Electronic Medicines Compendium (eMC). Bortox ${ }^{\circledR} 100$ units, Bortox ${ }^{\circledR}$ 50 units, Summary of Product Characteristics.Available from: https:// www.medicines.org.uk/emc/medicine/112; https://www.medicines. org.uk/emc/medicine/22562; https://www.medicines.org.uk/emc/ medicine/20564. Accessed January 2016.
5. Electronic medicines compendium (eMC). Xeomin ${ }^{\circledR} 100$ units, Xeo$\min \circledast 50$ units, summary of product characteristics. Available from: https://www.medicines.org.uk/emc/medicine/20666; https://www. medicines.org.uk/emc/medicine/24582. Accessed January 2016.

6. BNF: joint formulary committee. British national formulary (online); 2012. Available from: http://www.medicinescomplete.com. Accessed December, 2012.

7. PSS. Unit costs of health and social care 2011. and National Schedule of Reference Costs Year 2010-2011.Personal social services research unit (PSS); 2015. Available from: http://www.pssru.ac.uk. Accessed January 2016.

8. Office for national statistics (ONS). Annual Survey of Hours and Earnings, 2013 Provisional Results; 2013. Available from: http://www.ons. gov.uk/ons/dcp171778_335027.pdf.

9. Stacy M, Bloudek L, Schwartz M, Brin M, Papapetropoulos S. Cervical dystonia substantially impacts employment status, absenteeism, and presenteeism: Baseline results from cervical dystonia patient registry for the observation of onabotulinumtoxinA efficacy (CD PROBE). Mov Disord. 2012;(27):1106. 
ClinicoEconomics and Outcomes Research is an international, peerreviewed open-access journal focusing on health technology assessment, pharmacoeconomics and outcomes research in the areas of diagnosis, medical devices, and clinical, surgical and pharmacological intervention. The economic impact of health policy and health systems organization also constitute important areas of coverage. The manuscript management system is completely online and includes a very quick and fair peer-review system, which is all easy to use. Visit http://www.dovepress.com/testimonials.php to read real quotes from published authors.

Submit your manuscript here: https://www.dovepress.com/clinicoeconomics-and-outcomes-research-journal 